\section{SUBSTITUTION OF NITRIC FOR SULPHURIC ACID IN THE PRO- DUCTION OF PHOSPHATE FERTILIZERS}

\author{
By DR. G. R. DAVIES \\ Chemical Research Laboratory, Teddington
}

GULPHURIC acid is, perhaps, the most important $S$ of all chemicals, and the amount consumed usually provides a reliable index to the industrial virility of a country. In the United Kingdom the annual production of the acid has increased steadily over the years, rising in the past decade from about $1,200,000$ tons to more than $1,800,000$ tons in 1950 . More than fifty per cent of the recent production has been made from sulphur, the remainder being manufactured from pyrites, spent oxide, zinc concentrates and anhydrite. Native sulphur is the preferred raw material because of its high purity, low shipping costs and because of the lesser operating costs of plants burning sulphur as compared with those using pyrites. Considerable concern has therefore been caused in recent months by the statements which have been issued regarding the limited extent of the reserves of brimstone in the United States, which is the major producer of native sulphur. At the present rates of consumption these reserves may last only ten or eleven years. This has led the United States to reduce its exports, and British imports of sulphur have therefore been decreased by some thirty per cent. Although the reserve position in regard to pyrites is much more secure, yet any conversion of sulphur-burning plants to enable them to use pyrites must cause serious dislocation and must require some years to complete. The present position therefore calls for strict economy in the use of sulphuric acid.

'The largest consumer of the acid in Britain is the fertilizer industry, which last year used 435,500 tons in the manufacture of superphosphate, while a further 260,000 tons was employed in the manufacture of ammonium sulphate. A reduced production of sulphuric acid must lead to a decrease in the manufacture of artificial fertilizer and to a lowered productivity of British farm lands. Of course, there are numerous other users of sulphuric acid, such as the rayon industry, of which much has boen heard recently and which itself consumes more than 200,000 tons of aeid annually.

Because of the difficulties that might arise in maintaining adequate supplies of sulphuric acid to the fertilizer industry, the Chemical Research Laboratory, Teddington, has been studying for the past two years the possibility of making phosphate fertilizers by methods which might effect a saving in the amount of sulphuric acid used. The most obvious alternative to sulphuric acid is nitric acid, for its production does not call for the use of imported raw materials, while the nitrogen value of the acid is recoverable in the form of a nitrogenous fertilizer, and this offsets to some extent the greater cost of the acid as compared with sulphuric acid. Unfortunately, the action of nitric acid on phosphate rock leads to the production of a fertilizer containing much calcium nitrate, which is a highly hygroscopic substance and causes the fertilizer to become damp and difficult to use. Consequently, the work at the Chemical Research Laboratory has largely been confined to the use of mixtures of nitric and sulphuric acids. The action of these acids on phosphate rock leads to the formation of monocalcium phosphate, calcium sulphate and calcium nitrate, and there seemed the possibility that the inert calcium sulphate might so coat and protect the calcium nitrate as to prevent it absorbing moisture or, at least, that it would so slow down the rate of adsorption of moisture as to render the product usable without further treatment. Actually, it has been found that products made in this way are more stable to atmospheric conditions than when nitric acid is used alone. The maximum amount of nitric acid which can be tolerated in order to give a product having a low absorption of moisture is when the mixture of acids contains about $2 \mathrm{~mol}$. of nitric acid to one of sulphuric. Even with this mixture of acids the fertilizer made from it is somewhat hygroscopic if the theoretical amount of acid is used to decompose the rock completely, but when only eighty per cent of this amount is used the material does not pick up any appreciable amount of moisture at relative humidities below seventy per cent. The reaction between the phosphate rock and nitric-sulphuric acid mixtures is quite vigorous and goes to completion much more rapidly than when sulphuric acid is used alone as in ordinary superphosphate manufacture. The product also sets quickly to a dry, crumbly product, although it will dry out a little further in the course of a day or two. The fertilizer made in this way contains about 18 per cent of phosphate (reckoned as $\mathrm{P}_{2} \mathrm{O}_{5}$ ), of which 86 per cent is water-soluble, while 96 per cent is dissolved by 2 per cent nitric acid. The nitrogen content is about 4 per cent. There is very little evolution of hydrofluoric acid during the reaction and virtually no loss of nitric acid as nitrous fumes.

Attempts have been made to include potassium chloride in order to provide a complete fertilizer ; but with any substantial addition of this substance the products are more sensitive to atmosphere moisture.

A report on the work has been presented to the Fertilizer Manufacturers' Association.

\section{SCIENCE AND BREWING}

$\mathrm{W}$ HETHER brewing is an art or a science continues to be a question for debate; but it cannot be doubted that the impact of science on the brewing industry is becoming ever more insistent. Economic conditions are enforcing a more considered use of raw materials and plant; on the other hand, the selection of new barleys suited to changing agricultural conditions, malting for brewing, the selection and conservation of desirable yeasts, the development of acceptable disease-resistant hops and a better understanding of the many processes of mashing, fermentation, maturation and others making up what is colloquially known as brewing, are only a few of the numerous questions calling for scientific investigation. It was timely, therefore, when the Microbiological Group of the Society of Chemical Industry, the Incorporated Brewers' Guild and the Royal Microscopical Society held a symposium on brewing on March 14 in the Chemistry Department, King's College, Newcastle upon Tyne.

In an opening contribution on "Beer and the Biochemist", M. H. Van Gruisen (Newcastle Breweries, Ltd.) paid tribute to the help which science has given and is giving to the brewer in enabling him to produce a stable and uniform product from unstable 